\title{
Instruments of human resource management based on the digital technologies in Russia
}

\author{
Oksana Evseeva \\ High School of Management and \\ Business \\ Peter the Great St. Petersburg \\ Polytechnic University \\ St. Petersburg, Russia \\ evseeva@spbstu.ru \\ Kristina Plis \\ High School of Management and \\ Business \\ Peter the Great St. Petersburg \\ Polytechnic University \\ St. Petersburg, Russia \\ k.plis@igms.info
}

\author{
Olga Kalchenko \\ High School of Management and \\ Business \\ Peter the Great St. Petersburg \\ Polytechnic University \\ St. Petersburg, Russia \\ kalchenko_oa@spbstu.ru
}

\author{
Svetlana Evseeva \\ High School of Service and Trade \\ Peter the Great St. Petersburg \\ Polytechnic University \\ St. Petersburg, Russia \\ evseeva_sa@spbstu.ru
}

\begin{abstract}
The article is dedicated to the research on the use of digital instruments in human resource management in the leading Russian companies. The companies were chosen from the leading companies in their business field based on Ranking Top-100 leading companies in Russia on capitalization by the Agency Riarating in 2019. The authors stated that the most extensive for using digital technologies in human resources management at the moment is the $e$ recruitment process. The instruments of human resource management based on digital technologies in the sphere of erecruitment were linked with the 10 steps within the process in the chosen companies. Pros and Cons per each of the presented instruments were identified. In the conclusion it is said that digital technologies are actively used by companies around the world for recruitment, adaptation of employees and increase of labor efficiency. Russia is also no exception and is actively involved in these processes. In Russia, almost all large companies - market leaders use digital technologies in HR management, in particular, e-recruitment tools.

Keywords - digitalization; human resource management; recruitment; Russia; digital technologies
\end{abstract}

\section{INTRODUCTION}

Modern globalization trends, mobility, online business, high competition, high business speeds require companies to move to a new digital economy.

The upcoming digital revolution certainly requires a revision of the rules of business. New models of management are entering the competition, ensuring productivity, innovation, flexibility and adaptability. The foundation for this transition is the transformation of human resources (HR).

A new global trend, HR Digital, takes effect. The transition to digitalization is a new stage in the development of the HR industry and takes HR work to a new level of management, where they must apply modern digital tools [1].
The digitization of processes is relevant not only at the level of individual enterprises: there is a growing pressure from international and domestic network companies that are able to meet all new and new consumer demands as soon as possible[2].

Already, we can distinguish 5 of the most popular areas in HR-Digital: automation, analytics (payroll, job openings), marketing (benchmarking), online training and recruitment (E-recruitment) [3].

Turning to automation, it should be noted that the use of services and applications for automation is gaining momentum:

- Internal workflow.

- Recruiting: search and selection of candidates for vacancies.

- Evaluation and certification of company personnel.

- Staff training.

- Assessment of loyalty and involvement of staff.

- Monitoring the hr-brand of the company.

- HR analytics.

HR analytics has become a standard tool for most HR managers. All over the world, HR specialists and company executives are paying increasing attention to collecting and analyzing data about their employees. The use of Big Data and Data mining in the field of personnel management and the transformation of HR-data into successful business solutions, make it possible to work with factual information, predictive analytics and higher ROI HR. As for Russia, according to a study of the portal Rabota.ru, only $56 \%$ of Russian companies use HR analytics and only $7 \%$ have a full-time HR analyst.

HR marketing in the new economy uses digital tools in the following areas: the creation and promotion of an 
attractive HR employer brand; attracting and retaining talented employees; management of innovative projects and teams, the creation of HR content strategy: broadcasting the company's mission: "out" and "inside".

The next direction is online training. The emergence of new training programs within companies confirms the tendency that the development of employees' potential is inextricably linked with training. Organizations invent their own methods, create convenient systems within or customize market solutions. Microtraining, knowledge management, mentoring and mentoring, assessment of potential - these areas in 2019 continue their development.

The main trends in e-learning staff:

- Mobile learning.

- Adaptive learning using AI.

- Personalized training is the use of individual learning trajectories, the introduction of individual employee development plans.

- Evaluation of learning effectiveness: measuring the ROI of learning.

- Creating a developing environment that does not interfere with creativity and provides high results.

And finally, the last direction - recruitment. Erecruitment is already firmly established in the work of recruiters, and it is the field of recruiting that is the most extensive for using digital technologies at the moment: from automating the internship processes, evaluating candidates, selling and advertising vacancies to chat bots, robotsrecruiters. That is why the authors chose this direction for the study of cases using different tools at different stages of recruiting [4].

It is a widely spread view that human resources are the most important assets of organisations that influence not only the key performance indicators, but also the competitiveness $[5,6]$. An organization's ability to attract and retain talented employees may be the most important factor of organizational effectiveness. The recruitment function plays a crucial role in enhancing organizational survival and success in the extremely competitive and turbulent business environment [7]. Traditionally, organizations have used fairly low-tech methods to locate and attract qualified candidates, including newspaper ads and employee referrals. Later, the recruitment function has been undergoing dramatic changes as a result of ICTs development: "few markets have been hit as hard by the power of the Web and E-commerce as the recruiting industry. While there are still more changes underway, it's clear that the Web has quickly and dramatically changed the way the recruiting industry works" $[8,9]$.

Today, the Internet is one of the most popular ICT methods used in recruitment, although it is difficult to assess the actual level of recruitment through this source [10].

The Internet, the information availability and ICTs have radically changed recruiting [11], e.g. by significantly changing the traditional process of job advertising, CV screening, short-listing, and communication with candidates [12]. Practice shows that e-recruitment leads to a higher application turnover [13], significantly shortens the time required to fill a vacancy [14], and is highly cost-efficient [12]. Surveys show that job seekers increasingly looking to find work online, rather than through other sources [15].

E-recruitment is frequently discussed by practitioners and industry reports and is a widespread management topic worldwide.

The USA Society for Human Resource Management indicates that national online job boards and the career sections of company websites are the main recruiting sources for about half of companies [16]. According to Taleo Research (formerly iLogos Research) in 2001, 76\% of European 500 companies had a career section on their websites, $55 \%$ posted job positions there, and $55 \%$ accepted website submission of applications [17]. In 2003 Taleo Research survey concluded that $93 \%$ of Global 500 companies were using website recruitment: $96 \%$ of those in Pacific Asia, 94\% in Europe and 96\% in North America [18]. 2018 Corporate Recruiters Survey report is based on responses received from 1,066 employers in 42 countries worldwide and includes hiring results and projections overall, by region, industry, company size, and company type and confirms the same trends.

In the past ICTs in HR development were primarily educational media to support training, but now they are used to recruit, support learning at work, enhance job performance and facilitate organizational development and change [19].

E-recruitment is widespread in managerial practice and the second largest e-business application, however has received quite limited attention in academic research from an organizational point of view [20, 21]. E-recruitment and eHRM are relevant for the further empirical research [22].

It is difficult to find a clear and universally accepted definition of e-recruitment. The Dictionary of Human Resource Management defines e-recruitment as the recruitment of employees on the Internet [23]. According to the dictionary, e-recruitment assumes a number of different forms, including advertising vacancies on websites, Internet job boards that act as labour market intermediaries, and internet directories which list job vacancies and connect directly to company websites. Lee further broadens the definition by including a more general notion of electronic means which organizations employ to "fill open positions effectively and efficiently" [20]. It is still unclear which organizational processes and principles constitute efficient erecruiting practice, and how they are embedded in an organization.

E-recruitment is regarded as subordinate to e-HRM, also known as virtual HRM [24]. E-HRM is a way of implementing HRM for the acquisition, development and preservation of human capital using ICTs. E-recruiting goes beyond physical organizational boundaries, it is within the scope of ICTs and cyberspace. E-recruitment or Web-based recruitment forms a virtual part of an organization [18].

The first e-recruitment network business model was introduced by the Private Talent Network to support the practice of online recruitment. They conducted a study of six UK FTSE100 companies from different industries [25]. 
Application of ICTs in HRM systems is a prerequisite for any organization to successfully adopt and implement Fourth Industrial Revolution (Industry 4.0).

Blockchain technology that is based on distributed digital ledgers, can help facilitate the process of successfully effectuating HRM. Previously there were proposed a Blockchain based Recruitment Management System (BcRMS) and Blockchain based Human Resource Management System (BcHRMS) algorithm [26].

\section{MATERIALS AND METHODS}

Over the past two years, about $\$ 2$ billion has been invested in digital HR technologies in the world. And more will be invested. In 2019, according to the Fosway Group survey conducted among 500 large companies worldwide (Apple, Coca-Cola, Ericsson, Henkel, IBM, Nokia, Siemens, etc.), $68 \%$ of international employers plan to increase investment in analytics, 53\% - in digital tools in recruiting, as much - in the training and development of personnel. Russian employers also appreciated both the benefit of digital HR and its side effects.

The main question that authors state is what kind of digital instruments do Russian companies use in the process of recruitment to transform it into e-recruitment and what positive and negative effects or limitations they have per its use on different steps of recruitment.

The basic steps of recruitment investigated by authors in the research are presented on Fig.1.

\begin{tabular}{|c|}
\hline (1) Identifying the hiring need \\
\hline (4) Identifying viable candidates \\
(5) Recruiting of A-level candidates \\
(6) (Telephone) screening \\
(7) (Face-to-face) interviewing \\
(8) Offering of employment \\
\hline (9) Hiring of the candidate \\
\hline (10) Onboarding of the candidate \\
\hline
\end{tabular}

Fig. 1. Steps of recruitment process

Following the 10 steps we explored carefully cases of several companies on the Russian market that are the leading companies in their business field based on Ranking Top-100 leading companies in Russia on capitalization by the Agency Riarating in 2019 [27]: X5 Retail Group, Megafone, Rosatom, Sberbank, Auchan Retail Russia, KFC. Based on cases the authors correlated digital instruments to the steps of recruitment processes.

In our research, we present the exploratory case of the recruitment digital instruments aspects in the companies by describing the HR technologies.
An exploratory case study follows what is to be explored, the purpose of the exploration, and the criteria by which the exploration will be judged successful.

First, best companies based on official statistics were choosed. Based on cases the authors correlated digital instruments to the steps of recruitment processes.

As a result of the analysis, $7 \mathrm{HR}$ technologies were identified for more detailed analysis and identification of pros and cons. The content of the found technologies were described by qualitative comparative analysis.

\section{RESULTS}

\section{Robots (step 1-4,6, 10)}

The Russian trade network X5 Retail Group is the flagship in this field in Russia: it connected robot Vera to the primary personnel selection, capable of speaking and recognizing speech. Vera looks for resumes on recruiting sites according to the given parameters, calls potential applicants to the specified phones and tells them about the company's vacancies. If the candidate is interested, the robot informs employees of the HR department.

Vera can make 1500 calls a day, finding specialists who are ready to discuss employment. A recruiter would spend a few weeks on the same job. Also, X5 Retail Group recently transformed the technology - changed the robot's voice to a male one and made its intonation more cheerful. The new HR assistant is called Yermil and he acts just like Vera. Having identified a suitable candidate, immediately switches him to the recruitment service.

Coca-Cola HBC Russia is also successfully using the robot Vera, which took over the most resource-intensive routine functions of HR: pre-selection of candidates and primary call-down of applicants. A solution in Coca-Cola HBC Russia is also used in the onboarding of the candidate step - for example, to provide background information or conduct polls.

There is a place for artificial intelligence not only in the mass selection. Today's robots can track expert profiles even on social networks and make lists of those who are suitable for the company. Some programs still ask clarifying questions to selected people - via Facebook's message service and other instant messengers, and then broadcast the response to the HR manager. According to this scheme, for example, the robot FirstJob - Californian job search platform for beginners. According to the company, this IT solution saves up to $75 \%$ of the time of its HR team.

\section{Pros:}

The speed of searching for candidates increases several times, while the costs of primary data processing are reduced.

Cons:

Non-standard answers may not be perceived by the robot and the system may exclude a good candidate from the sample.

\section{Crowdsourced recruitment (Steps 1-4).}

Seven years ago, Rosatom and Witology implemented a project - they organized a crowdsourcing meeting of young 
atomic specialists to find, select and evaluate the most talented ones. The advantages of crowd recruiting (searching for candidates with the help of a wide range of people participating in a crowdsourcing project) are obvious, but it has not yet become a mass phenomenon in Russia - several projects were organized, in which more than 3000 people took part. Crowd recruiting takes place in several stages: first, the candidates get acquainted with the project's objectives, then each starts individual work, and then the participants team up and work together. All this can occur online, as was the case with Rosatom - the company used the Witology internet platform. With the help of crowdrecruiting, employers even hire rare specialists - scientists and engineers, for example, through the Filtered platform, which allows employers, using a special program, to observe how candidates solve complex problems while competing with each other.

Pros:

Crowd recruitment allows to hire a large number of young talented professionals, and in a short time. So, 4000 students and graduates from 280 universities from 450 Russian cities took part in the first crowdsourcing project of Rosatom. 250 of them received an offer for internship and work in the state corporation. There is another plus: people are often attracted from social networks to participate in crowdsourcing projects, which makes the company more recognizable. This allows you to save on advertising and PRpromotions, and also makes the image of the employer more attractive.

\section{Cons:}

By setting a specific production task for a collective decision, the employer, of course, wins - after all, he is able to quickly review and evaluate a large number of applicants for a vacancy. But crowd recruiting is definitely not suitable for single applicants who are used to working in peace and quiet and not rely on the help of colleagues. The ability to work effectively and quickly in a team of unfamiliar people is a special skill and even talent.

One of the most popular HR technologies in Russia is the VCV service (step 6-7), which allows candidates to record video responses to questions from the company's HR manager or recruiter. The one who has successfully passed this stage is sent for an interview to the company - as a rule, in a group interview where applicants meet with the recruiter already face to face.

In search of candidates for mass positions, employers began to use all possible channels in the world and are very active. For example, when connecting to the WiFi in the Moscow metro instead of the traditional advertising of consumer goods (if it is part of the target audience of the employer) it is a landing page for a job. Right there, on the phone or tablet, candidate can take a brief survey, the purpose of which is to weed out uninterested candidates. It is possible to see company vacancies in its mobile application - for example, from Sberbank. When a client sends a money transfer, advertising a vacancy by a Java developer will be shown to him, as well as "highlight" advantageous conditions, for example: flexible hours, work as part of agile teams and the lack of a dress code. MEGAPOLIS Group, the largest FMCG company in Russia, increased the speed of recruitment by 7 times with the help of VCV.

\section{Pros:}

VCV services allow to standardize the personnel selection process: candidates answer the same questions, which means they are in equal conditions. Also, recording responses to video allows you to significantly save companies hiring people in different cities and countries.

\section{Cons:}

Not all candidates trust such technologies as VCVservice. Many fear that their employers may see the video interview. They also refuse to record video due to lack of time, because in order to make a good impression even on a computer or phone screen, preparation is still needed. As a result, only a small proportion of high-quality job seekers reach companies.

\section{Messengers and social networks (steps 6-8)}

A year and a half ago, recruiters communicated with candidates mainly through e-mails. Today, they note, half of the 10 sent letters do not open half of the addressees if they see the topic "Job Offer". First of all, this concerns inactive candidates: if a person is already working and he has no plans to change the company, he perceives vacancy announcements as spam. But if you write to him in the messenger - is another matter, it is already considered as a personal message, and not as an advertisement. Therefore, about $50 \%$ of communications with candidates (and with customers), according to recruiters today, happens in Telegram, WhatsApp, any other instant messengers and even in Facebook messenger. Now this trend has reached office positions - instant messengers use when searching for candidates for various financial positions, in marketing, sales.

\section{Advantages:}

If you compare instant messengers and email-newsletter or tape on social networks, then the probability of viewing a vacancy in the first case increases significantly. According to Ericsson, more than $78 \%$ of Russians use messengers, that is, they check messages every day, which means the ad always reaches the addressee.

\section{Disadvantages:}

Not all instant messengers are technologically advanced and safe. Also, communication with candidates through them is only suitable when working with spot vacancies, for mass recruitment this is too time-consuming method.

\section{Voice bots (step 7)}

Auchan Retail Russia using a voice bot has increased the efficiency of recruiters, for a number of vacancies it was possible to reduce the closure period by $25 \%$. Automation of processes allowed to save $30 \%$ of the wages of the department of the selection department with an increase in the volume of work 4 times.

In 2017, KFC introduced a voice virtual assistant into its multifunctional automated recruiting system. The increase in conversion to an admitted employee was $11 \%$. 


\section{Advantages:}

Voice Assistant is able to handle 1 million requests per day, while its productivity is $24 / 7$. An indisputable advantage is the ability to control and analyze mass hiring of staff. Today, many customers choose customized solutions that allow to modify the product to fit their needs.

\section{Disadvantages:}

The negative reputation of interactive assistants - the duration of waiting, the lack of consideration of emotional intelligence.

\section{VR (Virtual Reality) and AR (Added Reality)}

Improving the technology and professional testing of applicants. Interesting possibilities for the assessment of competences are opened up, in particular, by the virtual and augmented reality. The positive effect of the use of VR \& AR-development is noted primarily in the mass selection. For example, in the USA and Australia, VR is actively used in hiring contract servicemen. In Russia, the first cases appeared quite recently.

It is known that some domestic companies offer candidates to demonstrate using VR their skills in assembling mechanisms or working on machine tools. For greater objectivity, the task is sometimes analyzed by means of additional technologies. In particular, during testing, the computer can "take" dozens of indicators from the applicant - from speed of movement to heart rate. It helps to understand how emotionally stable and confident he is in his actions.

Of course, in Russia, the use of VR \& AR solutions for interviews is still not widespread. But it is already clear that this is a good support in the work of HR, which saves time and effort for both the company and the potential employee.

The authors also identified universal digital technologies, covering all stages of recruitment. These include ATSsystems (Applicant Tracking Systems) - special online platforms that help manage the flow of candidate resumes, conduct interviews, bring together a team of recruiters, collect and process answers, analyze the recruitment process and much more. There are several well-known domestic ATS- Huntflow, Potok, and there are international ones, for example, SuccessFactors. Even large Russian telecommunications companies are coming to this market in early December last year, Megafon announced the creation of its own ATS project Megafon Recruiting.

\section{Advantages:}

The obvious advantage of ATS is the speed at which they process candidate data. But the main advantage of ATS is that they are integrated with the outside world: all responses from job search sites and social networks automatically fall into the system, while both recruiters and hiring managers work in the same interface. Some ATS have additional functions - you can send emails to candidates from the system, make appointments and confirm meetings.

Disadvantages:

Automated resume review is quick, but not always effective. For example, if a candidate has work experience of 3 years and 11 months, and the program selects only those who have at least 4 years experience in this position, then this candidate automatically drops out of the list of applicants for a vacancy. Although he may have a lot of advantages over those who meet the requirements for experience. For example, an excellent education or additional certificates, courses, knowledge of a foreign language.

\section{Universal platforms based on artificial intelligence}

An example of such a platform in the Russian market is Skillaz, an automated cloud-based recruiting platform based on artificial intelligence. The service allows you to significantly reduce the cost of closing a position and improve the quality of hiring in the company by providing a full range of tools at all stages of recruitment - automatic search and preliminary assessment of candidates, video interview recording, security checks, bidding, Skillas is already actively used by many large Russian companies Sberbank, Megafon, KPMG, Gazprom Neft.

\section{Advantages:}

Automation and centralization of processes leads to saving time and budget for the company.

\section{Disadvantages:}

The inability to work with candidates for higher positions due to the inability to assess the human factor, empathy and other elements of emotional intelligence

\section{DISCUSSION}

Digital technologies are actively used by companies around the world for recruitment, adaptation of employees and increase of labor efficiency. Russia is also no exception and is actively involved in these processes. As a rule, HR departments of market leaders can afford to experiment with technological solutions today. This trend, however, is gradually changing from an experimental approach to a focused one: large and medium businesses are beginning to look at technology not as a beautiful toy, but as a useful tool that makes it possible to establish itself among competitors, motivate employees, increase the attractiveness of the employer, save the company's budget, staff time and highlight the really standing candidates against the rest. In Russia, almost all large companies - market leaders use digital technologies in HR management, in particular, erecruitment tools.

The only step in the process of hiring staff that is currently not actively using digital technology, or is using a limited amount, is step 5 - recruiting of A-level candidates because this candidates are always unique, have absolutely different motivation and need individual approach. A lot of depends on EQ - level of emotional intellect for the top positions. This competence is currently not identified by digital tools.

Most of the instruments are used on several steps of recruitment processes, only several ones are focused only on one step (step7). There is also the tendency of the use of universal tools - platforms for all of the steps of recruitment.

One of the world's largest retail brands has already integrated social media tools into its hiring strategy [28]. 
HR professionals can best use social media in recruitment [29]. It is essential for organizations to consider adding social media to their overall recruitment strategy to meet the goals of being cost - effective, targeted, and strategic; staying competitive; and recruiting the best.

The possibilities of social network sites use as an erecruitment tool are already studied [30]. The online recruitment method has a lot of benefits but also pitfalls that recruiters need to be aware of. A well-designed system and strategic utilization of available information about potential candidates can greatly facilitate the recruitment of employees with the most suitable skills and competencies.

\section{CONCLUSIONS}

Many companies with large staff and relevant staffing needs are showing interest in digital technology today. So far, digital solutions presented on the Russian market are quite expensive and require pinpoint refinements. But in the future, the volume of their use is likely to be sufficient.

The growing volume of investments confirms that "digital" HR is a serious and for a long time. Possession of his tools for the recruiter, and now it is necessary, and in the near future will form the basis of the profession. Except when a candidate needs to speak with a human being - in every sense of the word. Business will have to actively invest in employees: help them overcome the fear of the universal emergence of artificial intelligence and retrain, increasing digital literacy.

As limitations it should be mentioned that we took only example of Russia and based only on data in open access. It could be one of the prospective - to analyze the usage of each digital HR tool in different international companies in other countries. Also as perspective directions for further research, it also seems appropriate to apply the aboveanalyzed tools for government organizations.

\section{ACKNOWLEDGMENT}

This paper was financially supported by the Ministry of Education and Science of the Russian Federation on the programm to improve the competitiveness of Peter the Great St.Petersburg Polytechnic University (SPbPU) among the world's leading research and education centres in the 20162020 .

\section{REFERENCES}

[1] A.R. Bril, O.V. Kalinina, I.V. Ilin " Economic Analysis of Projects in the Improvement of the HR Management System of Enterprises", Proceedings of the 29th International Business Information Management Association Conference - Sustainable Economic Growth, Education Excellence, and Innovation Management through Vision 2020, 2017, pp. 2268-2277.

[2] V.V. Glukhov,I.V. Ilin, A.B. Anisiforov. "Problems of data protection in industrial corporations enterprise architecture". ACM International Conference Proceeding Series 8. "Proceedings of the 8th International Conference on Security of Information and Networks, SIN 2015", 2015.

[3] Semenova A.N., Stupkina V.A. Digital Technologies in Management human resources // Young scientist. - 2019. - №4. - p. 250-252. URL https://moluch.ru/archive/242/55864/ (appeal date: 06/20/2019).

[4] HR Digital: trends and technologies of 2019, which HRs are talking about. [Online]. Available:http://hr-elearning.ru/hr-digital-trendy-itekhnologii-2019-goda-o-kotorykh-govoryat-hr/
[5] Pfeffer, Jeffrey, and Francois Villeneuve. Competitive advantage through people: Unleashing the power of the workforce. Vol. 61. Boston, MA: Harvard Business School Press, 1994.

[6] Kankovskaya, A., Kalinina, O., Ilin, I. Economics of transport and sustainable development: Problems of high education in Russia (2018) MATEC Web of Conferences, 239, 08008.

[7] Kozlov, A., Teslya, A. (2017) Human factors for development of corporate internal social investments Portfolio. Advances in Intelligent Systems and Computing, 2017.

[8] Kay, Christine, and John Russette. "Hospitality-management competencies: Identifying managers' essential skills." Cornell Hotel and Restaurant Administration Quarterly 41.2 (2000): 52-63.

[9] Singh, P., \& Finn, D. (2003). The effects of information technology on recruitment. Journal of Labor Research, 24(3), 395-408.

[10] Kari, Jarkko, and Reijo Savolainen. "Relationships between information seeking and context: A qualitative study of Internet searching and the goals of personal development." Library \& Information Science Research 29.1 (2007): 47-69.

[11] Cappelli, Peter. "Making the most of on-line recruiting." Harvard business review 79.3 (2001): 139-148.

[12] Coleman, James. "The adolescent society." Education Next 6.1 (2006).

[13] Minton-Eversole, T. "E-recruitment comes of age, survey says." HRMagazine 52.8 (2007): 34.

[14] Taylor, Mark P. "Self-employment and windfall gains in Britain: evidence from panel data." Economica 68.272 (2001): 539-565.

[15] Bartram, Dave. "Internet recruitment and selection: Kissing frogs to find princes." International journal of selection and assessment 8.4 (2000): 261-274.

[16] Friedman, Barry A. "Human resource management role implications for corporate reputation." Corporate Reputation Review 12.3 (2009): 229-244.

[17] Lermusiaux, Yves, Alice Snell, and Stephen Jones. "Best practices for european 500 career web site recruiting." Taleo Research (2001).

[18] Holm, A. B. (2012). E-recruitment: towards an ubiquitous recruitment process and candidate relationship management. German Journal of Human Resource Management, 26(3), 241-259.

[19] Benson, A. D., Johnson, S. D., \& Kuchinke, K. P. (2002). The use of technology in the digital workplace: A framework for human resource development. Advances in Developing Human Resources, 4(4), 392404.

[20] Lee, In. "The evolution of e-recruiting: a content analysis of Fortune 100 career websites." Journal of Electronic Commerce in Organizations (JECO) 3.3 (2005): 57-68.

[21] Parry, Emma, and Shaun Tyson. "An analysis of the use and success of online recruitment methods in the UK." Human Resource Management Journal 18.3 (2008): 257-274.

[22] Kuporov, Y.Y., Avduevskaya, E.A., Bogacheva, T.V. Investments in human capital: Efficiency of investments in higher education in Russia (2018) pp. 926-940.

[23] Heery, E., and M. Noon. "E-recruitment." Dictionary of Human Resource Management, Oxford University Press, Oxford (2001): 112.

[24] Lepak, David P., and Scott A. Snell. "Virtual HR: Strategic human resource management in the 21 st century." Human resource management review 8.3 (1998): 215-234.

[25] Allden, N., \& Harris, L. (2013). Building a positive candidate experience: Towards a networked model of e-recruitment. Journal of Business Strategy, 34(5), 36-47.

[26] Vinogradova, E.Yu., Andreeva, S.L., Babkin, A.V., Galimova, A.I. Corporate information system - Element of efficient human resources management of the industrial-economic complex (2017) 2018January, pp. 63-66.

[27] Top 100 krupneishih po kapitalizacii kompanii Rossii [TOP 100 largest Russian companies by capitalization - Rating 2019], [Online]. Available:

http://www.riarating.ru/infografika/20190129/630115992.html.

[28] Doherty, R. (2010). Getting social with recruitment. Strategic HR review, 9(6), 11-15.

[29] Madia, S. A. (2011). Best practices for using social media as a recruitment strategy. Strategic HR Review, 10(6), 19-24. 
[30] Melanthiou, Y., Pavlou, F., \& Constantinou, E. (2015). The use of social network sites as an e-recruitment tool. Journal of Transnational
Management, 20(1), 31-49. 